\title{
CRESCIMENTO EACÚMULO DE FÓSFORO PELA SOJA CULTIVADA EM SUCESSÃOA DIFERENTES GRAMÍNEAS FORRAGEIRAS ADUBADAS COM SUPER FOSFATO TRIPLO E FOSFATO REATIVO DEARAD
}

\author{
Phosphorus fractions and soybean yield in succession to grasses fertilized \\ with different phosphorus sources \\ Carlos Ribeiro Rodrigues ${ }^{1}$, Valdemar Faquin², Fabrício William de Ávila ${ }^{3}$, \\ Tatiana Michlovská Rodrigues ${ }^{4}$, Danielle Pereira Baliza ${ }^{3}$, Eliezer Augusto Baeta de Oliveira ${ }^{3}$
}

\begin{abstract}
RESUMO
Conduziu-se este trablho, com o objetivo de avaliar o efeito do cultivo prévio de diferentes gramíneas forrageiras, adubadas com superfosfato triplo (SFT) e fosfato reativo de arad (FRA), sobre o crescimento, produção e acúmulo de P pela soja. Foram realizados dois experimentos, um em Cambissolo Háplico tb distrófico típico e o outro em Latossolo Vermelho distrófico típico textura muito argilosa. Para os dois experimentos, o delineamento experimental foi o inteiramente casualizado em esquema fatorial 4 × $2+2$, sendo o cultivo prévio de quatro gramíneas forrageiras (Brachiaria decumbens Stapf - braquiária, Brachiaria brizantha Hochst Stapf - braquiarão, milheto e sorgo forrageiro) adubadas com duas fontes de P (FRA e SFT) e dois tratamentos adicionais que é o cultivo da soja sem o cultivo prévio de plantas de cobertura e adubadas com SFT e FRA. As plantas foram colhidas após completar o ciclo de desenvolvimento. Foram determinadas a produtividade de grãos (PG) e de massa seca da parte aérea (MSPA) e o acúmulo de fósforo na parte aérea e nos grãos da soja, as forrageiras imobilizaram o P do SFT, reduzindo o efeito residual para a soja e o feijoeiro. Quando as gramíneas forrageiras foram adubadas com o FRA, houve um aumento do efeito residual, com aumento da produtividade da soja em sucessão às plantas de cobertura, com exceção para o cultivo em sucessão ao braquiarão.
\end{abstract}

Termos para indexação: Efeito residual, adubação fosfatada, Glycine max e Phaseolus vulgaris.

\begin{abstract}
The objective of this study was to evaluate the effect of the previous cultivation of different forage grasses fertilized with triple superphosphate (TSP) and reactive Arad phosphate (RAP) on growth, yield, and accumulation of P by soybean. Two experiments were carried out ; one in Haplic Cambisol typical tb distrophic, medium texture and the other in Red Latosol typical distrophic very clayey texture. For both experiments, the experimental design was a completely randomized one in a $4 \times 2+2$ factorial scheme; the previous crop being of four forage grasses utilized as cover plants in no-tillage system (Brachiaria decumbens Stapf - braquiária, Brachiaria brizantha Hochst Stapf - braquiarão, millet and forage sorghum) fertilized with two sources of P (RAP and TSP) and two additional treatments, which are the cultivation of soybean and bean plant without the previous growing of cover plants, and also fertilized with TSP and RAP. The plants were harvested after they had completed the development cycle. Grain and shoot dry matter yield and $\mathrm{P}$ accumulation in the shoot and in the grains of soybean were determined. The forage plants immobilized the P of TSP, reducing the residual effect for soybean. When forage grasses are fertilized with RAP, there is increased residual effect with increasing yield of soybean in succession to the cover plants, with exception for the growing in succession to Brachiaria brizanta.
\end{abstract}

Index terms: residual effect, phosphate fertilizer, Glycine max and Phaseolus vulgaris.

(Recebido em 27 de abril de 2006 e aprovado em 21 de outubro de 2008)

\section{INTRODUÇÃO}

Uma das maiores dificuldades de se instalar o Sistema de Plantio Direto (SPD) no cerrado, tem sido a escolha de culturas de inverno para manutenção da palhada. Aliado a esse fator, o manejo da adubação fosfatada nessa região, também, é muito complexo, sendo o solo o dreno preferencial para o ânion fosfato, o que compete fortemente com o dreno planta pelo nutriente, reduzindo a produtividade das culturas.

O aumento da deposição de resíduos vegetais na superfície do solo e a ausência de revolvimento resultam

\footnotetext{
'Eng. Agrônomo, Doutor em Solos e Nutrição de Plantas, Prof. Fertilidade do Solo e Nutrição de Plantas da Universidade Federal Rural de Pernambuco Unidade Acadêmica de Garanhuns - carlos_rrodrigues@yahoo.com.br

Eng. Agrônomo, Doutor em Solos e Nutrição de Plantas, Prof. Nutrição de Plantas do Depto. de Ciência do Solo da Universidade Federal de Lavras vafaquin@dcs.ufla.br

${ }^{3}$ Mestrando, Universidade Federal de Lavras.

${ }^{4}$ Enga . Agrônoma, Dra. Fitotecnia. Bolsista Pós-doutotado CAPES/PNPD/UFU/ICIAG - Uberlândia, MG.
} 
em complexas modificações na fertilidade do solo no SPD (Pádua et al., 2008). Há um aumento considerável nos teores dos nutrientes, principalmente o $\mathrm{P}$, em superfície, em razão da deposição de material vegetal (Menezes et al., 2002). Sendo que, as aplicações anuais de fertilizantes fosfatados, a liberação de $\mathrm{P}$ durante a decomposição dos resíduos vegetais e a redução da adsorção específica do $\mathrm{P}$ em decorrência do menor contato do nutriente com os constituintes inorgânicos do solo, resultam na acumulação superficial desse nutriente em sistema de plantio direto (Muzilli, 1996; Lana et al., 2007).

$\mathrm{O}$ uso de plantas de cobertura eficientes em reciclar o P também vem sendo estudado, principalmente em espécies utilizadas como forrageiras na região Sul do país, como aveia-preta, mucuna preta, ervilhaca e tremoço. No entanto, Borket et al. (1999) demonstraram que nenhuma dessas plantas apresentou potencial para reciclagem do $\mathrm{P}$. O uso do SPD em solos sob ecossistema cerrado foi possível, segundo Bernardi et al. (2003), em razão da utilização de plantas de cobertura com alto potencial de produção de biomassa, como o milheto, capim pé-degalinha e, recentemente, com a maior divulgação e utilização do sistema Santa Fé e Integração Agricultura Pecuária, o uso de plantas do gênero Brachiaria. No entanto, são raros os estudos que avaliam o efeito do cultivo dessas espécies sobre as frações de $\mathrm{P}$ do solo, a eficiência na reciclagem de $\mathrm{P}$ e, consequentemente, a disponibilidade desse nutriente para as culturas subsequentes. Recentemente, Francisco (2002) e Seguatelli (2004) avaliaram a produtividade da soja em semeadura direta com antecipação da adubação fosfatada na cultura de Eleusine coracana (L.) Gaertn. (Capim pé-de-galinha). Esses autores relatam que, sob as condições em que foram instalados os experimentos, a adubação fosfatada da soja antecipada para o capim pé-de-ganilha, além de proporcionar maior produção de fitomassa da planta de cobertura, não alterou a produção de grãos da soja, o que beneficia o sistema implantado, e não só a cultura de verão. Broch (1997, 2000), Pitol et al. (2001) e Kluthcouski \& Stone (2003) relatam que, em diversas áreas sob ecossistema cerrado nos estados do Mato Grosso do Sul e Goiás, a soja apresenta maiores produções sobre palhada de plantas do gênero Brachiaria, principalmente em sucessão à Brachiaria brizantha.

Nesse sentido, conduziu-se este projeto, com o objetivo de avaliar a produção e nutrição fosfatada da soja cultivada em sucessão a diferentes gramíneas forrageiras adubadas com superfosfato triplo e fosfato reativo de arad.

\section{MATERIALE MÉTODOS}

Foram utilizadas amostras $(0-20 \mathrm{~cm})$ dos solos Cambissolo Háplico tb distrófico típico textura média e Latossolo Vermelho distrófico típico textura muito argilosa. A soja foi cultivada em vasos de cinco $\mathrm{dm}^{3}$ de capacidade contendo quatro $\mathrm{dm}^{3}$ de solo.

$\mathrm{O}$ delineamento experimental utilizado foi o inteiramente casualizado em esquema fatorial $4 \times 2+2$, sendo os quatro tratamentos de cobertura dos solos, representadas pelo cultivo prévio das quatro forrageiras (Brachiaria decumbens Stapf - braquiária, Brachiaria brizantha Hochst Stapf - braquiarão, milheto e sorgo forrageiro), duas fontes de P (Superfosfato triplo - SFT e Fosfato reativo de arad - FRA) e mais dois tratamentos adicionais (adição do SFT e do FRA sem cultivo prévio das forrageiras). Os tratamentos adicionais foram representados pelos dois solos adubados com as fontes de $\mathrm{P}$, na mesma época dos tratamentos com as gramíneas de cobertura, mas que não foram cultivados, permanecendo, portanto, em pousio durante o cultivo prévio das gramíneas forrageiras. Foram utilizadas quatro repetições para todos os tratamentos.

As amostras dos solos foram secas ao ar e peneiradas em malha de quatro mm de abertura. Após, subamostras foram tomadas para caracterizações física, química, mineralógica e das formas de P (Tabela 1). Com base nas análises químicas, foi efetuada a calagem nos solos visando a elevar a saturação por bases a 50\%, utilizando-se um calcário dolomítico calcinado e micropulverizado, com $35 \%$ de $\mathrm{CaO}$, $14 \%$ de $\mathrm{MgO}$ e PRNT $=100 \%$.

Após incubação dos solos por 20 dias, em umidade próxima à $60 \%$ do volume total de poros (VTP), as fontes de fósforo (SFT e FRA) foram incorporadas nos quatro $\mathrm{dm}^{3}$ de solo do vaso, nas doses de 150 e $250 \mathrm{mg} \mathrm{dm}^{-3}$ de $\mathrm{P}$ para o Cambissolo e Latossolo, respectivamente, considerando o teor de $\mathrm{P}$ total das fontes (Tabela 2). Pretendeu-se para as duas fontes (SFT e FRA), aplicar doses de $\mathrm{P}$ menores que as adequadas, segundo recomendadas por Alvarez \& Fonseca (1990). Nessa mesma época, foi efetuada uma adubação básica com $80 \mathrm{mg}$ de $\mathrm{N}$, $80 \mathrm{mg}$ de K, $60 \mathrm{mg}$ de S, 0,5 mg de B, 1,5 mg de Cu e $5 \mathrm{mg}$ de $\mathrm{Zn}$ por $\mathrm{dm}^{3}$ de solo, sob a forma de solução nutritiva. Foram utilizadas as fontes p.a.: $\left(\mathrm{NH}_{4}\right)_{2} \mathrm{SO}_{4}, \mathrm{KNO}_{3}, \mathrm{NH}_{4} \mathrm{NO}_{3}, \mathrm{H}_{3} \mathrm{BO}_{3}$, $\mathrm{CuSO}_{4} \cdot 5 \mathrm{H}_{2} \mathrm{O}$ e $\mathrm{ZnSO}_{4} \cdot 7 \mathrm{H}_{2} \mathrm{O}$.

Em seguida, foram semeadas 10 sementes por vaso de cada forrageira e desbastadas para quatro plântulas uma semana após a emergência. Durante o cultivo, as forrageiras receberam adubações nitrogenada e potássica em cobertura, aplicando-se $400 \mathrm{mg} \mathrm{dm}^{-3}$ de cada nutriente para a $B$. brizantha e $B$. decumbens e $500 \mathrm{mg} \mathrm{dm}^{-3}$ de cada nutriente para o sorgo e milheto, parceladas em sete aplicações. 
Tabela 1 - Caracterizações química e física do Latossolo Vermelho distrófico típico e Cambissolo Háplico Tb distrófico típico antes da aplicação dos tratamentos.

\begin{tabular}{|c|c|c|}
\hline Atributos & Latossolo & Cambissolo \\
\hline $\mathrm{pH} \mathrm{H} \mathrm{H}_{2} \mathrm{O}(1: 2,5)$ & 4,7 & 5,4 \\
\hline $\mathrm{P}\left(\mathrm{mg} \mathrm{dm}^{-3}\right)$ & 0,9 & 0,6 \\
\hline $\mathrm{K}\left(\mathrm{mg} \mathrm{dm}{ }^{-3}\right)$ & 20,0 & 20,0 \\
\hline $\mathrm{Ca}\left(\mathrm{cmol}_{\mathrm{c}} \mathrm{dm}^{-3}\right)$ & 0,6 & 0,7 \\
\hline $\mathrm{Mg}\left(\mathrm{cmol}_{\mathrm{c}} \mathrm{dm}^{-3}\right)$ & 0,2 & 0,2 \\
\hline $\mathrm{Al}\left(\mathrm{cmol}_{\mathrm{c}} \mathrm{dm}^{-3}\right)$ & 1,1 & 0,7 \\
\hline $\mathrm{H}+\mathrm{Al}\left(\mathrm{cmol}_{\mathrm{c}} \mathrm{dm}^{-3}\right)$ & 7,0 & 2,3 \\
\hline $\mathrm{SB}\left(\mathrm{cmol}_{\mathrm{c}} \mathrm{dm}^{-3}\right)$ & 0,9 & 1,0 \\
\hline (t) $\left(\mathrm{cmol}_{\mathrm{c}} \mathrm{dm}^{-3}\right)$ & 2,0 & 1,7 \\
\hline (T) $\left(\mathrm{cmol}_{\mathrm{c}} \mathrm{dm}^{-3}\right)$ & 7,9 & 3,3 \\
\hline $\mathrm{V}(\%)$ & 10,8 & 29,2 \\
\hline $\mathrm{M}(\%)$ & 56,0 & 42,0 \\
\hline $\mathrm{MO}\left(\mathrm{dag} \mathrm{kg}^{-1}\right)$ & 4,9 & 2,1 \\
\hline P-rem $\left(\mathrm{mg} \mathrm{dm}^{-3}\right)$ & 10,2 & 25,2 \\
\hline Areia $\left(\right.$ dag kg $\left.^{-1}\right)$ & 21,0 & 55,0 \\
\hline Silte $\left(\right.$ dag kg $\left.^{-1}\right)$ & 9,0 & 16,0 \\
\hline Argila $\left(\right.$ dag $\left.\mathrm{kg}^{-1}\right)$ & 70,0 & 29,0 \\
\hline Classe Textural & Muita Argilosa & Média \\
\hline $\mathrm{SiO}_{2}\left(\mathrm{~g} \mathrm{~kg}^{-1}\right)$ & 129,8 & 144,0 \\
\hline $\mathrm{Al}_{2} \mathrm{O}_{3}\left(\mathrm{~g} \mathrm{~kg}^{-1}\right)$ & 319,1 & 155,0 \\
\hline $\mathrm{Fe}_{2} \mathrm{O}_{3}\left(\mathrm{~g} \mathrm{~kg}^{-1}\right)$ & 171,8 & 23,0 \\
\hline $\mathrm{TiO}_{2}\left(\mathrm{~g} \mathrm{~kg}^{-1}\right)$ & 22,0 & 3,0 \\
\hline $\mathrm{P}_{2} \mathrm{O}_{5}\left(\mathrm{~g} \mathrm{~kg}^{-1}\right)$ & 0,9 & 0,1 \\
\hline $\mathrm{Ki}\left(\mathrm{SiO}_{2} / \mathrm{Al}_{2} \mathrm{O}_{3}\right)$ & 0,41 & 1,57 \\
\hline $\mathrm{Kr}\left(\mathrm{SiO} 2 / \mathrm{Al}_{2} \mathrm{O}_{3}+\mathrm{Fe}_{2} \mathrm{O}_{3}\right)$ & 0,26 & 1,43 \\
\hline
\end{tabular}

P e K - Extrator Mehlich I; Ca, Me e Al - Extrator KCl 1N; H+Al - Extrator SMP; SB - Soma de Bases; (t) - CTC efetiva; (T) - CTC potencial (a pH 7,0); V - saturação por bases; $\mathrm{m}$ - saturação por alumínio; P-rem - Fósforo remanescente; $\mathrm{MO}$ - oxidação $\mathrm{Na}_{2} \mathrm{Cr}_{2} \mathrm{O}_{7}$ $4 \mathrm{~N}+\mathrm{H}_{2} \mathrm{SO}_{4} 10 \mathrm{~N}$ (Embrapa, 1999).

${ }^{1}$ Resultados da análise mineralógica dos solos apresentados, para o Cambissolo, por Giarola (1994) e, para o Latossolo (Souza, 2005).

Tabela 2 - Composição química e física dos fertilizantes fosfatados.

\begin{tabular}{ccccccc}
\hline \multirow{2}{*}{ Fonte } & $\mathrm{P}_{2} \mathrm{O}_{5}$ & \multicolumn{3}{c}{$\mathrm{P}_{2} \mathrm{O}_{5}$ solúvel } & \multirow{2}{*}{ CaO } & Granulometria \\
\cline { 3 - 5 } & Total & água & CAN+água & Cítrico ${ }^{1}$ & & Granulado \\
\cline { 3 - 6 } SFT & 46,1 & 38,8 & 46,1 & - & 13,0 & Farelado \\
FRA & 33,1 & - & - & 9,4 & 37,0 & . \\
\hline
\end{tabular}

${ }^{1}$ Ácido cítrico a 2\% (1:100) 
As forrageiras de cobertura foram cultivadas até o préflorescimento, quando a parte aérea foi cortada a dois $\mathrm{cm}$ da superfície do solo. A parte aérea das forrageiras foi seca em estufa a $65-70^{\circ} \mathrm{C}$ para a obtenção da palhada que foi utilizada como cobertura para o cultivo subsequente da soja. Após secas em estufa, as amostras da parte aérea das forrageiras foram picadas em pedaços de três a cinco centímetros, sendo aplicadas na superfície dos solos dos vasos correspondentes, na dose de $8 \mathrm{t} \mathrm{ha}^{-1}$ de matéria seca (Corrêa et al., 2004), correspondendo $27,7 \mathrm{~g} \mathrm{vaso}^{-1}$ (raio de $10,5 \mathrm{~cm})$.

Após a deposição da palhada nos vasos, foi efetuada adubação básica na forma de solução nutritiva com $70 \mathrm{mg}$ de N, $50 \mathrm{mg}$ de K, $30 \mathrm{mg}$ de S, 0,5 mg de B, 1,5 mg de $\mathrm{Cu}$ e $5 \mathrm{mg}$ de $\mathrm{Zn}$ por $\mathrm{dm}^{3}$, usando as mesmas fontes p.a. citadas para as forrageiras. Em seguida, foram semeadas 10 sementes de soja, sendo desbastadas para duas plântulas uma semana após a emergência. Até a fase de florescimento da soja foram aplicados em cobertura 230 $\mathrm{mg}$ de N, $200 \mathrm{mg}$ de K e $30 \mathrm{mg}$ de $\mathrm{S}$ por $\mathrm{dm}^{3}$, parcelados em cinco aplicações. Durante todo o período experimental, a umidade do solo foi mantida a $60 \%$ do VTP, por meio de pesagem dos vasos e adição de água deionizada. A colheita da soja foi feita no final do ciclo, secando-se o material vegetal em estufa a $65-70^{\circ} \mathrm{C}$, para a obtenção da massa seca da parte aérea e de grãos. Na parte aérea e nos grãos da soja, foram realizadas análises químicas para o P de acordo com Malavolta et al. (1997). Relacionando os teores de $\mathrm{P}$ com a massa seca produzida, foram determinados o acúmulo de $\mathrm{P}$ na parte aérea e nos grãos da soja.

Os dados experimentais foram submetidos à análise de variância e testes de média com auxílio do programa estatístico SISVAR ${ }^{\circledR}$. As médias dos tratamentos componentes do fatorial foram comparadas entre si pelo teste de Scott-Knott $(P \leq 0,05)$. As médias dos tratamentos adicionais foram comparadas com as médias dos tratamentos do fatorial por contraste $(P \leq 0,05)$.

\section{RESULTADOS E DISCUSSÃO}

Em geral, a produção de grãos (PG) e de massa seca de parte aérea (MSPA) da soja foi maior no Latossolo (Figura $1 \mathrm{a}, \mathrm{b}, \mathrm{c}$ e d).

Na Tabela 3, observa-se que quando aplicado o FRA, no Latossolo, a PG da soja cultivada em sucessão às forrageiras foi semelhante à $\mathrm{PG}$ da soja cultivada no tratamento sem cultivo. Já no Cambissolo, a PG da soja em sucessão à braquiária, milheto e sorgo, foi superior ao tratamento sem cultivo. Esse resultado permite inferir que o efeito residual do FRA foi maior no Cambissolo, corroborando com a afirmativa de Goedert (1983) e Magalhães (1984), quando relatam que o efeito residual do P oriundo de fontes de baixa solubilidade é mais intenso em solos arenosos. Outro resultado que apóia essa afirmativa, são os altos valores da fração de $\mathrm{P}$ ligada a Ca (P-HCl) observados no Cambissolo, após o cultivo do milheto, do sorgo, da braquiária e do braquiarão, segundo Rodrigues (2006). O autor também observou que o braquiarão, sorgo e milheto adubados com FRA, no Cambissolo, reduziram os teores da fração $\mathrm{P}-\mathrm{HCl}$ em relação ao tratamento sem cultivo, sendo que o braquiarão foi a planta que mostrou-se mais eficiente na aquisição do P fornecido pelo FRA. No entanto, como a soja foi semeada e cultivada logo após o corte das forrageiras, esse tempo, provavelmente, não foi suficiente para a decomposição e mineralização do $\mathrm{P}$ da palhada das forrageiras. Moraes (2001) apresenta a taxa de mineralização do $\mathrm{P}$ da palhada do milheto e sorgo, onde 93 e $88 \%$, respectivamente, do nutriente acumulado em cada palhada eram liberados após 168 dias após deposição, e que seriam necessários 182 e 183 dias para a mineralização completa de todo o $\mathrm{P}$ da palhada do milheto e sorgo, respectivamente. $\mathrm{O}$ autor ainda relata que a taxa média de mineralização do $\mathrm{P}$ da palhada do milheto e do sorgo foi 0,100 e $0,102 \mathrm{~kg} \mathrm{ha}^{-1} \mathrm{dia}^{-1}$. Kluthcouski \& Stone (2003) relatam que a palhada de plantas do gênero Brachiaria apresenta alta longevidade, quando, após 120 dias da dissecação ainda apresentava cobertura completa do solo e com 10,2 t ha ${ }^{-1}$ de palha, ou seja, o período de cultivo da soja, não foi suficiente para a mineralização do $\mathrm{P}$ na palhada.

Quando aplicado o FRA, no Latossolo, somente em sucessão ao braquiarão, a soja apresentou redução significativa da PG e, no Cambissolo, somente em sucessão ao braquiarão a produção não foi superior (Tabela 3). Ou seja, quando as forrageiras foram adubadas com o FRA, em ambos os solos a produção da soja em sucessão ao braquiarão foi inferior à produção da soja em sucessão às demais plantas (Figura $1 \mathrm{a} \mathrm{e} \mathrm{b}$ ).

Na Figura 1, a e b, observa-se variação significativa da $\mathrm{PG}$ da soja em função da fonte de $\mathrm{P}$ somente em sucessão ao braquiarão, sendo a menor produção quando aplicado o FRA. A baixa produção da soja em sucessão ao braquiarão pode estar relacionada a algum efeito da constituição química da palhada, no entanto, os dados do presente trabalho não dão suporte a essa discussão. 
Tabela 3 - Estimativa dos contrastes de médias para a produção de grãos (PG) (g planta-1) e massa seca de parte aérea (MSPA) $\left(\mathrm{g} \mathrm{planta}^{-1}\right)$ da soja entre os tratamentos sem cultivo prévio das forrageiras de cobertura versus os tratamentos com cultivo de cobertura adubadas com SFT e FRA.

\begin{tabular}{|c|c|c|c|c|c|}
\hline \multirow{3}{*}{ Contrastes } & \multicolumn{3}{|c|}{ Latossolo } & \multicolumn{2}{|c|}{ Cambissolo } \\
\hline & Grãos & \multicolumn{2}{|c|}{ MSPA } & Grãos & MSPA \\
\hline & & ------------ & $-\left(\right.$ g vaso $\left.^{-1}\right)$ & ---------- & \\
\hline \multirow{4}{*}{$\begin{array}{l}\text { Sem Cultivo com } \\
\text { SFT vs. }\end{array}$} & Braquiária SFT & $13,82^{* * 1}$ & $14,99^{* *}$ & $11,40^{* *}$ & $14,33^{* *}$ \\
\hline & $\begin{array}{l}\text { Braquiarão } \\
\text { SFT }\end{array}$ & $15,60^{* *}$ & $17,21^{* *}$ & $14,54^{* *}$ & $15,83^{* *}$ \\
\hline & Milheto SFT & $17,98^{* *}$ & $10,35^{* *}$ & $12,84^{* *}$ & $7,10^{*}$ \\
\hline & Sorgo SFT & $17,16^{* *}$ & $18,75^{* *}$ & $11,56^{* *}$ & $10,25^{* *}$ \\
\hline \multirow{4}{*}{$\begin{array}{l}\text { Sem Cultivo com } \\
\text { FRA vs. }\end{array}$} & $\begin{array}{l}\text { Braquiária } \\
\text { FRA }\end{array}$ & $-2,62^{\text {ns }}$ & $-21,26^{* *}$ & $-8,52^{* *}$ & $-16,44^{* *}$ \\
\hline & $\begin{array}{l}\text { Braquiarão } \\
\text { FRA }\end{array}$ & $5,64^{*}$ & $-9,63^{* *}$ & $0,60^{\mathrm{ns}}$ & $-17,85^{* *}$ \\
\hline & Milheto FRA & $-4,37^{\mathrm{ns}}$ & $-21,01^{* *}$ & $-13,78^{* *}$ & $-24,80^{* *}$ \\
\hline & Sorgo FRA & $-3,04^{\mathrm{ns}}$ & $-24,70^{* *}$ & $-16,07^{* *}$ & $-16,02^{* *}$ \\
\hline
\end{tabular}

**, *, Ns - Significativo a 1, $5 \%$ e não singinificativo, respectivamente, pelo teste de F.

${ }^{1}$ Os valores correspondem à diferença das médias entre os tratamentos adicionais, sem cultivo versus os tratamentos com cultivo das forrageiras, adubados com SFT e o FRA. Quando negativos, a média da diferença obtida no tratamento com cultivo das forrageiras foi superior à média obtida no tratamento adicional, sem cultivo.

\section{LATOSSOLO}

(a)

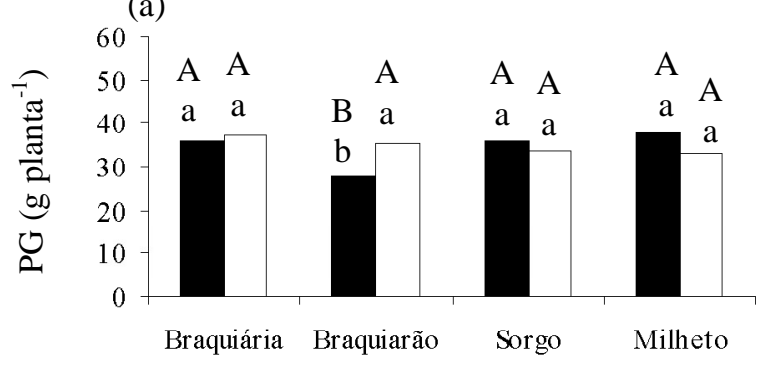

(c) $\mathrm{A}$

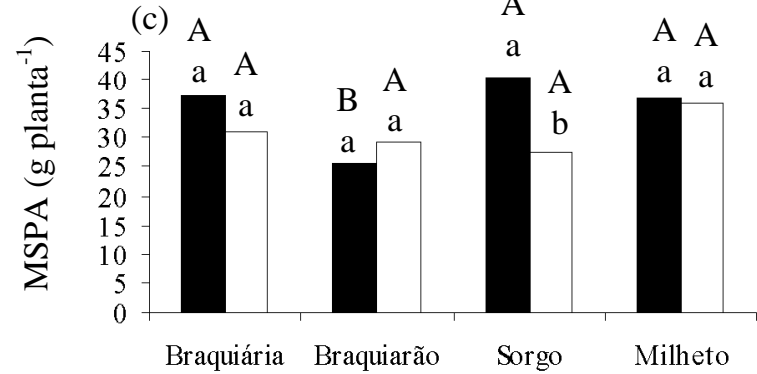

(b)

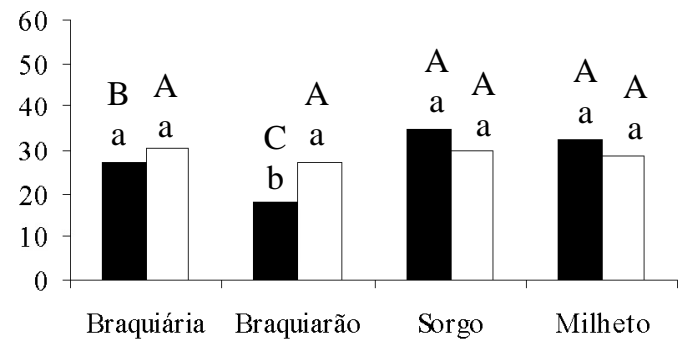

(d)

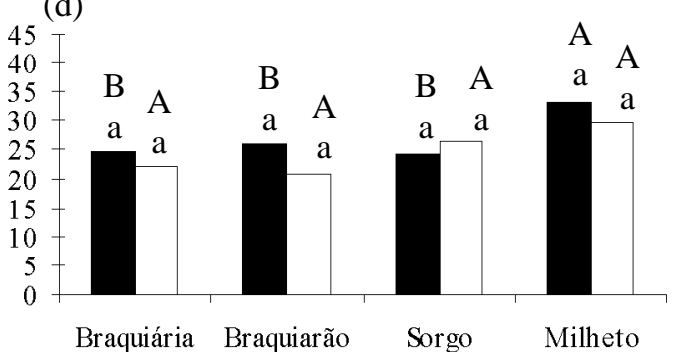

Figura 1 - Produção de grãos (PG) (a b) e de matéria seca de parte aérea (MSPA) (c e d) da soja cultivada em sucessão a plantas de cobertura adubadas com SFT e FRA, no Latossolo e no Cambissolo. Em cada solo, médias seguidas de mesma letra, minúscula, comparando as fontes de P para cada gramínea forrageira, e maiúscula, comparando as gramíneas forrageiras em cada fonte de $\mathrm{P}$, não diferem entre si (Scott-Knott 5\%). 
Em razão da melhor distribuição do sistema radicular, o braquiarão proporciona melhor distribuição da matéria orgânica e, consequentemente, melhor distribuição do nutriente reciclado Kluthcouski \& Stone (2003). Rodrigues (2006) observaram que, quando adubado com o FRA, o braquiarão, no Latossolo, apresentou a menor resposta em crescimento de raiz em relação às demais forrageiras e, no Cambissolo, o segundo menor rendimento em crescimento de raiz.

Quando aplicado o SFT não se observou influência do cultivo prévio das plantas de cobertura sobre a PG da soja em ambos os solos. Quando as forrageiras foram adubadas com o FRA, a menor produção da soja foi obtida quando cultivada em sucessão ao braquiarão (Figura 1 a e b).

Comparando a MSPA da soja, nos tratamentos sem e com cultivo das forrageiras, observa-se que, quando aplicado o FRA, em ambos os solos, a soja apresentou maior MSPA em sucessão às forrageiras, evidenciando o efeito residual do FRA (Tabela 3). Quando aplicado o SFT, a MSPA da soja em sucessão às forrageiras foi inferior à obtida no tratamento sem cultivo (Tabela 3 ).

No Latossolo, somente o cultivo da soja em sucessão ao sorgo apresentou alteração significativa para a fonte de $\mathrm{P}$, sendo a menor MSPA obtida quando aplicado o SFT (Figura $1 \mathrm{c}$ ). No Cambissolo, não foi observada nenhuma alteração significativa para a fonte de P. (Figura $1 \mathrm{~d}$ ).

No Latossolo, quando aplicado o FRA, a menor MSPA da soja foi obtida com o cultivo sucessão ao braquiarão (Figura 1 c), e no Cambissolo, com a soja cultivada em sucessão à braquiária, ao braquiarão e ao sorgo (Figura $1 \mathrm{~d}$ ). Quando aplicado o SFT, em ambos os solos não foi observada diferença significativa do cultivo prévio das forrageiras sobre a MSPA da soja (Figura $1 \mathrm{c} \mathrm{d}$ ).

Com relação ao acúmulo de $\mathrm{P}$ na parte aérea e nos grãos da soja, comparando os valores obtidos nos tratamentos sem e com cultivo prévio das plantas de cobertura, observa-se que, quando aplicado o FRA, houve aumento no acúmulo de $\mathrm{P}$ na parte aérea e nos grãos da soja cultivada em sucessão à braquiária, sorgo e milheto, em ambos os solos (Tabela 4). Para o cultivo da soja em sucessão ao braquiarão adubado com o FRA, observa-se, no Latossolo, redução do acúmulo de $\mathrm{P}$ nos grãos e para o acúmulo de $\mathrm{P}$ na parte aérea não se observou alteração significativa (Tabela 4). No Cambissolo, o acúmulo de $\mathrm{P}$ nos grãos da soja cultivada em sucessão ao braquiarão adubado com FRA foi semelhante ao valor obtido na soja sem cultivo prévio de planta de cobertura (Tabela 4). Quando aplicado o SFT, o acúmulo de P na parte aérea e nos grãos da soja cultivada em sucessão às forrageiras foi inferior aos valores obtidos na soja sem cultivo prévio das plantas de cobertura em ambos os solos, com exceção, no Cambissolo, do acúmulo de $\mathrm{P}$ na parte aérea da soja cultivada em sucessão ao milheto que foi semelhante ao valor obtido no tratamento sem cultivo (Tabela 4).

Semelhante ao observado para a PG e MSPA, o acúmulo de $\mathrm{P}$ na parte aérea e nos grãos da soja foi superior no Latossolo em relação ao Cambissolo (Figura 2 a, b, c e d).

Tabela 4 - Estimativa dos contrastes de médias para o acúmulo de $\mathrm{P}$ nos grãos $\left(\mathrm{g} \mathrm{vaso}^{-1}\right)$ e na parte aérea da soja ( $\mathrm{g}$ vaso $^{-1}$ ) entre o tratamentos sem cultivo prévio das forrageiras de cobertura versus (vs.) os tratamentos com cultivo de cobertura adubadas com SFT e FRA.

\begin{tabular}{|c|c|c|c|c|c|}
\hline \multirow[b]{2}{*}{ Contrastes } & & \multicolumn{2}{|c|}{ Latossolo } & \multicolumn{2}{|c|}{ Cambissolo } \\
\hline & & Grãos & P.Aérea & Grãos & P.Aérea \\
\hline \multirow{4}{*}{ Sem Cultivo com SFT vs. } & Braquiária SFT & $0,0706^{* * 1}$ & $0,0158^{* *}$ & $0,0700^{* *}$ & $0,0109^{* *}$ \\
\hline & Braquiarão SFT & $0,0934^{* *}$ & $0,0195^{* *}$ & $0,1200^{* *}$ & $0,0149^{* *}$ \\
\hline & Milheto SFT & $0,1018^{* *}$ & $0,0116^{* *}$ & $0,0600^{* *}$ & $0,0000^{\mathrm{ns}}$ \\
\hline & Sorgo SFT & $0,1180^{* *}$ & $0,0182^{* *}$ & $0,0800^{* *}$ & $0,0097^{* *}$ \\
\hline \multirow{4}{*}{ Sem Cultivo com FRA vs. } & Braquiária FRA & $-0,0328^{* *}$ & $-0,0126^{* *}$ & $-0,0500^{* *}$ & $-0,0100^{* *}$ \\
\hline & Braquiarão FRA & $0,0357^{* *}$ & $-0,0038^{\mathrm{ns}}$ & $0,0100^{\mathrm{ns}}$ & $-0,0110^{* *}$ \\
\hline & Milheto FRA & $-0,0306^{* *}$ & $-0,0141^{* *}$ & $-0,0600^{* *}$ & $-0,0120^{* *}$ \\
\hline & Sorgo FRA & $-0,0256^{*}$ & $-0,0108^{* *}$ & $-0,0500^{* *}$ & $-0,0064^{* *}$ \\
\hline
\end{tabular}

**,*, NS - Significativo a 1, $5 \%$ e não singinificativo, respectivamente, pelo teste de $\mathrm{F}$.

${ }^{1}$ Os valores correspondem à diferença das médias entre os tratamentos adicionais, sem cultivo versus os tratamentos com cultivo das forrageiras, adubados com SFT e o FRA. Quando negativos, a média da diferença obtida no tratamento com cultivo das forrageiras foi superior à média obtida no tratamento adicional, sem cultivo. 
Avaliando o efeito das fontes de $\mathrm{P}$ sobre o acúmulo de P na parte aérea da soja, observa-se, no Latossolo, que os maiores valores foram obtidos quando a soja foi cultivada em sucessão à braquiária, sorgo e milheto adubadas com o FRA (Figura 2 a). No Cambissolo, não houve diferença significativa para o acúmulo de $\mathrm{P}$, na parte aérea da soja, entre as fontes de $\mathrm{P}$ (Figura $2 \mathrm{~b}$ ). No Latossolo, quando aplicado o FRA, o acúmulo de P na parte aérea da soja cultivada em sucessão ao braquiarão apresentou o menor valor e, no Cambissolo, não foi observada diferença significativa (Figura 2 a e b). Quando aplicado o SFT, o acúmulo de $\mathrm{P}$ na parte aérea da soja em sucessão à braquiária, ao braquiarão e ao sorgo apresentaram os menores valores (Figura 2 a e b).

Para o acúmulo de $\mathrm{P}$ nos grãos da soja, observa-se diferença significativa entre as fontes somente no cultivo da soja em sucessão ao braquiarão no Latossolo, apresentando o menor acúmulo quando aplicado o FRA (Figura 2 c e d). Quando aplicado o FRA, em ambos os solos, os menores valores de acúmulo de $\mathrm{P}$ nos grãos foram obtidos com o cultivo em sucessão ao braquiarão (Figura 2 c e d). Quando adubadas com o SFT, no Latossolo, os menores valores de acúmulo de $\mathrm{P}$ nos grãos da soja foram obtidos com o cultivo em sucessão ao braquiarão, sorgo e milheto e, no Cambissolo, em sucessão ao braquiarão (Figura 2 c e d).

Em geral, os dados das Figuras 1 para massa seca e 2 para o acúmulo de $\mathrm{P}$ pela soja mostram que, de maneira geral, para os dois solos, independente da forrageira de cobertura, as fontes de $\mathrm{P}$ utilizadas não influenciaram o crescimento, produção e acúmulo de $\mathrm{P}$ pela soja cultivada em sucessão. Nas Tabelas 3 para produção de grão e massa seca de parte aérea e 4 para acúmulo de $\mathrm{P}$ na parte aérea e grãos da soja, mostra-se que de maneira geral, independente do solo utilizado, o cultivo prévio das forrageiras de cobertura reduziu o crescimento e acúmulo de $\mathrm{P}$ pela soja, quando a fonte de P foi o SFT e, ao contrário, foi observado quando a fonte foi o FRA, com exceção para o cultivo em sucessão ao braquiarão.

A longo prazo, em termos práticos, a integração lavoura-pecuária pode reduzir ainda mais o efeito residual de fontes de $\mathrm{P}$ solúvel, em razão da exportação dos nutrientes na forragem consumida pelos animais. Nesse caso, o uso de fontes de menor solubilidade seria boa

\section{LATOSSOLO}

(a) $\mathrm{A}$

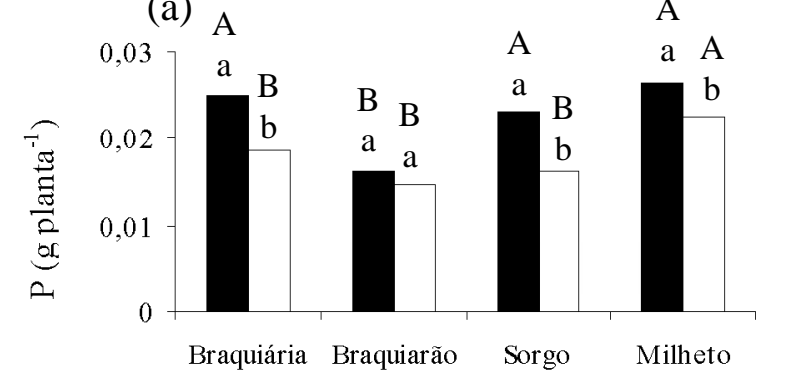

(c) $\mathrm{A}$

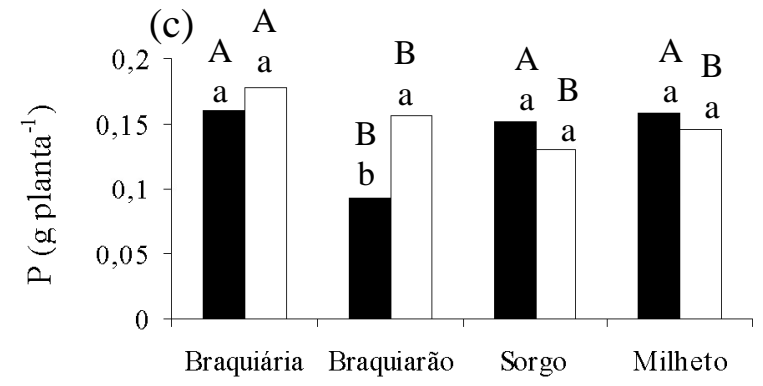

\section{CAMBISSOLO}

(b)

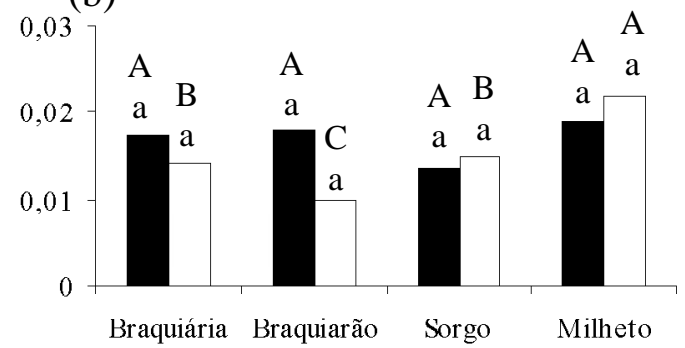

(d)

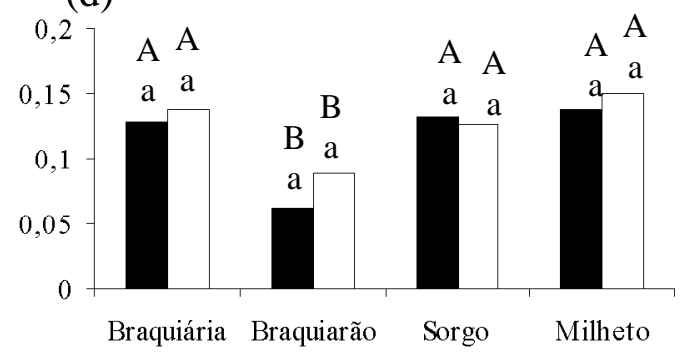

Figura 2 - Acúmulo de P na parte aérea (a b) e nos grãos (c d) da soja cultivada em sucessão a plantas de cobertura adubadas com SFT e FRA, no Latossolo e no Cambissolo. Em cada solo, médias seguidas de mesma letra, minúscula, comparando as fontes de $\mathrm{P}$ para cada gramínea forrageira, e maiúscula, comparando as gramíneas forrageiras em cada fonte de $\mathrm{P}$, não diferem entre si (Scott-Knott 5\%). 
alternativa, possibilitando maior efeito residual e melhor aproveitamento do $\mathrm{P}$ da fonte, decorrente de uma liberação mais lenta para a solução do solo, reduzindo a fixação e aumentando o aproveitamento do nutriente pela cultura em sucessão.

Em geral, o efeito do fator dreno de $\mathrm{Ca}$ no Latossolo foi preponderante nos resultados e, com isso, potencializando a aplicação de fosfatos reativos em solos argilosos e com alta CTC potencial, apresentando resultados semelhantes aos obtidos, quando aplicadas fontes solúveis de P, como o SFT. No entanto, quando cultivado em solos com baixo fator dreno de $\mathrm{Ca}$, solos arenosos de baixa CTC potencial, a eficiência de fontes de $\mathrm{P}$ menos solúveis como o FRA, fica dependente do uso de plantas com maior eficiência na absorção de $\mathrm{P}$ e $\mathrm{Ca}$, como o braquiarão e a braquiária. No entanto, o manejo da fertilidade do solo por meio da calagem e de adubações periódicas, pode alterar algumas propriedades químicas do solo, afetando a reação de dissolução dos fertilizantes fosfatados, principalmente das fontes menos reativas.

\section{CONCLUSÃO}

Os resultados do presente trabalho permitem concluir que: as forrageiras imobilizaram o P do SFT, reduzindo o efeito residual para a soja e, quando as gramíneas forrageiras foram adubadas com o FRA, houve um aumento do efeito residual, com aumento da produção da soja em sucessão às plantas de cobertura, com exceção para o cultivo em sucessão ao braquiarão.

\section{AGRADECIMENTOS}

Ao CNPq e FAPEMIG pelo apoio financeiro.

\section{REFERÊNCIAS BIBLIOGRÁFICAS}

ALVAREZ, V.H.; FONSECA, D.M. da. Definição de doses de fósforo para determinação da capacidade máxima de adsorção de fosfatos e para ensaios em casa de vegetação. Revista Brasileira de Ciência do Solo, Campinas, v.14, p.49-55, 1990.

BERNARDI, A.C.C.; MACHADO, P.L.O.A.; FREITAS, P.L.; COELHO, M.R.; LEANDRO, W.M.; OLIVEIRA JÚNIOR, J.P.; OLIVEIRA, R.P.; SANTOS, H.G.; MADARI, B.E.; CARVALHO, M.C.S. Correção do solo e dubação no sistema de plantio direto nos cerrados. Rio de Janeiro: Embrapa Solos, 2003. 22p. (Embrapa Solos. Documentos, 46).
BORKET, C.M.; GAUDÊNCIO, C.A.; PEREIRA, J.E.; OLIVEIRA JUNIOR, A. Nutrientes minerais na biomassa da parte aérea de culturas de cobertura de solo para semeadura direta com rotação de culturas (compact disc). In: CONGRESSO BRASILEIRO DE CIÊNCIA DO SOLO, 27., 1999, Brasília, DF. Anais... Brasília, DF: Embrapa-CPAC, 1999. CD-ROM.

BROCH, D.L. Soja PD em brachiária. Direto no Cerrado, Brasília, v.2, n.4, p.8-9, 1997.

BROCH, D.L. Integração agricultura-pecuária no CentroOeste do Brasil. In: ENCONTRO REGIONAL DE PLANTIO DIRETO NO CERRADO, 4., 1999, Uberlândia, MG. Plantio direto na integração lavoura-pecuária. Uberlândia: UFU, 2000. p.53-60.

CORRÊA, J.C.; MAUAD, M.; ROSOLEM, C.A. Fósforo no solo e desenvolvimento de soja influenciados pela adubação fosfatada e cobertura vegetal. Pesquisa Agropecuária Brasileira, Brasília, v.39, n.12, p.12311237, dez. 2004.

\section{EMPRESA BRASILEIRA DE PESQUISA}

AGROPECUÁRIA. Embrapa Solos. Embrapa Informática Agropecuária. Manual de análises químicas de solos, plantas e fertilizantes. Brasília, DF, 1999. 370p.

FRANCISCO, E.A.B. Antecipação da adubação da soja na cultura de Eleusine coracana (L.) Gaertn em sistema de plantio direto. 2002. 58p. Dissertação (Mestrado)Escola Superior de Agricultura Luiz de Queiroz, Piracicaba, 2002.

GIAROLA, N.F.B. Levantamento pedologico, perdas de solo e aptidao agricola das terras na regiao sob influencia do reservatorio de Itutinga/Camargos (MG). 1994. 226f. Dissertação (Mestrado)-Escola Superior de Agricultura de Lavras, Lavras, 1994.

GOEDERT, W.J. Efeito residual de fosfatos naturais em solos de cerrado. Pesquisa Agropecuária Brasileira, Brasília, v.18, p.499-506, 1983.

KLUTHCOUSKI, J.; STONE, L.F. Desempenho de culturas anuais sobre palhada de braquiária. In: KLUTHCOUSKI, J.; STONE, L.F.; AIDAR, H. Integração lavoura-pecuária. Santo Antônio de Goiás: Embrapa Arroz e Feijão, 2003. p.499-522. 
LANA, R. M. Q.; BUCK, G. B.; LANA, A. M. Q.; PEREIRA, R. P. Doses de multifosfato magnesiano aplicados a lanço em pré-semeadura, sob sistema plantio direto - cultura da soja. Ciência e Agrotecnologia, Lavras, v.31, n.6, p.1654-1660, nov./dez. 2007.

MAGALHÃES, J.C.A.J. Aproveitamento do fosfato-depatos-de-minas pelo trigo (Triticum aestivum $\mathrm{L}$.) $\mathrm{cv}$. IAC-5, cultivado em dois solos sob vegetação de cerrado do DF, com dois níveis de calagem. 1984. 202f. Tese (Doutorado)-Escola Superior de Agricultura Luiz de Queiroz, Piracicaba, 1984.

MALAVOLTA, E.; VITTI, G.C.; OLIVEIRA, S.A. de. Avaliação do estado nutricional das plantas: princípios e aplicações. 2.ed. Piracicaba: Potafos, 1997. 319p.

MENEZES, L.A.; SOUTO JÚNIOR, M.L.; LEANDRO, W.M. Efeitos de coberturas verdes, com potencial de utilização em sistema de plantio direto, na variabilidade espacial de nutrientes no solo. In: FERTBIO, 2002, Rio de Janeiro, RJ. Resumos... Rio de Janeiro: UFRRJ, 2002. CDROM.

MORAES, R.N. de S. Decomposição das palhadas de sorgo e milheto, mineralização de nutrientes e seus efeitos no solo e na cultura do milho em plantio direto. 2001. 90p. Dissertação (Mestrado)-Universidade Federal de Lavras, Lavras, 2001.
MUZILLI, O. Influência do sistema de plantio direto, comparado ao convencional, sobre a fertilidade da camada arável do solo. Revista Brasileira de Ciência do Solo, Campinas, v.20, n.3, p.407-414, 1996.

PÁDUA, T. R. de P.; SILVA, C. A.; DIAS, B. de O. Nutrição e crescimento do algodoeiro em latossolo sob diferentes coberturas vegetais e manejo de calagem.

Ciência e Agrotecnologia, Lavras, v.32, n.5, p.1481-1490, set./out. 2008.

PITOL, C.; GOMES, E.L.; ERGES, E.I. Avaliação de cultivares de soja em plantio direto sobre brachiária. In: FUNDAÇÃO MS. Resultados de pesquisa e experimentação: safra 2000/2001. Maracaju, 2001. p.40-48.

RODRIGUES, C.R. Frações de fósforo e produção da soja e do feijoeiro em sucessão a gramíneas adubadas com diferentes fertilizantes fosfatados. 2006. 113p. Tese (Doutorado)-Universidade Federal de Lavras, Lavras, 2006.

SEGUATELLI, C.R. Produtividade da soja em semeadura direta com antecipação da adubação fosfatada e potássica na cultura de Eleusine coracana (L.) Gaertn. 2004. 58p Dissertação (Mestrado)-Escola Superior de Agricultura Luiz de Queiroz, Piracicaba, 2004.

SOUZA, R.F. de. Dinâmica de fósforo em solos sob influência da calagem e adubação orgânica, cultivados com feijoeiro. 2005. 141p. Tese (Doutorado)Universidade Federal de Lavras, Lavras, 2005. 